\title{
Glucocorticoids indirectly decrease colon cancer cell proliferation and invasion via effects on cancer-associated fibroblasts
}

\author{
Zuzanna Drebert $^{\mathrm{a}, \mathrm{b}}$, Elly De Vlieghere ${ }^{\mathrm{a}, \mathrm{b}}$, Jolien Bridelance ${ }^{\mathrm{c}}$, Olivier De Wever ${ }^{\mathrm{a}, \mathrm{b}}$, \\ Karolien De Bosscher ${ }^{\mathrm{b}, \mathrm{d}}$, Marc Bracke ${ }^{\mathrm{a}, \mathrm{b}}$, Ilse M. Beck ${ }^{\mathrm{a}, \mathrm{b}, \mathrm{e}, *}$ \\ ${ }^{a}$ Laboratory of Experimental Cancer Research, Department of Radiation Oncology \& Experimental Cancer Research, Ghent University, Ghent, Belgium \\ ${ }^{\mathrm{b}}$ Cancer Research Institute Ghent (CRIG), Ghent, Belgium \\ ${ }^{c}$ Molecular Signaling and Cell Death Unit, VIB Center for Inflammation Research, Ghent University, Ghent, Belgium \\ d Receptor Research Laboratories, Nuclear Receptor Lab, VIB Center for Medical Biotechnology, Department of Biochemistry, Ghent University, Ghent, Belgium \\ e Department Health Sciences, Odisee University College, Ghent, Belgium
}

\section{A R T I C L E I N F O}

\section{Keywords:}

Glucocorticoids

Cancer-associated fibroblasts (CAFs)

Colon cancer

Cancer cell proliferation

Cancer cell invasion

\begin{abstract}
A B S T R A C T
Cancer-associated fibroblasts (CAFs) support cancer growth, invasion, and metastasis. Glucocorticoids (GCs), drugs often administered together with chemotherapy, are steroidal ligands of the glucocorticoid receptor (GR), a transcription factor which upon activation regulates expression of multiple genes involved in suppression of inflammation. We have previously shown that in dexamethasone (Dex)-treated CAFs derived from colon cancer, production and secretion of several factors related to cancer progression, such as tenascin C (TNC) and hepatocyte growth factor (HGF), were strongly suppressed.

In this study we show that GCs can neutralize the cancer cell-promoting properties of CAFs. Conditioned medium from solvent-treated CAFs (CM $\left.{ }^{\mathrm{CTRL}}\right)$ stimulates proliferation, motility and stretched morphotype of GRdeficient HCT8/E11 colon cancer cells. Yet, HCT8/E11 proliferation and stretched morphotype are impaired upon treatment with conditioned medium from Dex-treated CAFs (CM ${ }^{\mathrm{DEX}}$ ), but HCT8/E11 cell migration is slightly increased under these conditions. Moreover, expression and potential activity of MMP-2 is also reduced in $\mathrm{CM}^{\mathrm{DEX}}$ compared with $\mathrm{CM}^{\mathrm{CTRL}}$. These combined in vitro results concur with the results from in vivo chick chorioallantoic membrane assays, where the co-cultures of CAFs with colon cancer cells displayed impaired tumor formation and cancer cell invasion due to Dex administration. Combined, GC treatment influences cancer cell behavior indirectly through effects on CAFs.
\end{abstract}

\section{Introduction}

Colorectal cancer (CRC) is one of the most common malignant neoplastic diseases in Europe and Northern America [1]. CRC's morbidity is linked to western dietary lifestyle, age, obesity, smoking, alcohol consumption, lack of physical activity, and certain hereditary diseases [2]. Despite an improvement in treatment, CRC accounted for nearly $10 \%$ of cancer-related deaths in 2012 [1].

Cancer development is driven by sustained proliferative signaling, resistance to apoptosis and to growth suppressors, angiogenesis, escape from immune response, reprogramming of metabolism, invasion, and metastasis [3]. Last decades' progress in cancer research was enhanced by an improved understanding of the importance of the tumor microenvironment. Stromal components including inflammatory cells, cells forming tumor vasculature and lymphatics, myofibroblasts, and the extracellular matrix are not passive bystanders. On the contrary, they play a crucial role in virtually every step of cancer progression. Researching this complex net of interactions between certain components of the tumor microenvironment creates opportunities for diagnosis and therapy $[3,4]$.

Myofibroblasts of the tumor stroma, which contribute to cancer progression are also known as cancer-associated fibroblasts (CAFs) [5]. They mostly differentiate from resident fibroblasts and share attributes of smooth muscle cells and fibroblasts and express markers, such as $\alpha$ smooth muscle actin, fibroblast activation protein- $\alpha$ and vimentin [6]. CAFs are recruited by cancer cells at the invasion front of the tumor and influence cancer cells via cell-to-cell contact or via secreted products, such as cytokines, chemokines, enzymes, and other factors $[7,8]$. CAFs are abundantly present in CRC compared to normal mucosa, both at primary and metastatic sites, which is related to poor overall and relapse-free survival [9]. CAFs were shown to contribute to the following tumor-promoting actions: cancer proliferation, induction of

\footnotetext{
* Correspondence to: Department Health Sciences, Odisee University College, Gebroeders de Smetstraat 1, 9000 Gent, Belgium.

E-mail address: Ilse.Beck@odisee.be (I.M. Beck).
} 
angiogenesis, protection from anti-tumor immune responses, activation of invasion, and promotion of metastasis [10].

Depending on the type and stage of the cancer different types of treatment are implemented. Most often patients receive a combination of therapies, which include surgery, radiation therapy, chemotherapy, immunotherapy, targeted therapy, hormone therapy, and stem cell transplant [11]. Cancer treatment, however, faces problems of therapy resistance, which can be also triggered by cancer stroma. Environmentmediated drug resistance (EMDR), whereby CAFs protect cancer cells by secreting a multitude of cytokines is linked with cancer aggressiveness and poor response to treatment [12].

Glucocorticoids (GCs) are drugs that are often used in combination with chemotherapy, hormonal therapy, radiotherapy, and surgery of solid tumors, in order to relieve symptoms of the disease and the associated side-effects of these treatments [13]. GCs are steroidal compounds, essential in regulating metabolism, blood pressure, reaction to stress, and immune response [14]. GCs are able to bind and activate the glucocorticoid receptor (GR). Ligand-bound GR is translocated from the cytoplasm to the nucleus, where it acts as a homodimerized transcription factor to positively regulate expression of numerous specific target genes by binding to glucocorticoid responsive elements (GREs). Furthermore, GR in its monomeric form can tether other transcription factors, such as NFKB or AP-1, resulting in inhibition of transcription of many pro-inflammatory genes. These two major mechanisms are known respectively as transactivation and transrepression [15,16]. GR actions result in suppression of inflammation and therefore GCs are widely used in the clinic against many inflammatory disorders, such as asthma, allergies, and autoimmune diseases [15,16]. Besides their anti-inflammatory properties, GCs also serve as angiostatic agents in infantile hemangiomas $[14,17]$ and form a treatment of hematological malignancies, such as multiple myeloma and lymphoma [18]. The role of GR modulation in solid tumor biology, however, is still not fully understood. This is also a topic of controversy, since the result of GC treatment depends on the primary site of the tumor and extends from possible detrimental effects in lung cancer, over neutral in gastrointestinal cancer to positive effects in prostate cancer [19]. Interestingly, GR mRNA levels are elevated in the stroma of breast cancer, compared to the healthy breast tissue. Moreover, in breast cancer, there is a positive correlation between GR mRNA levels in the tumor stroma and the tumor stage $[13,20]$. Lastly, approximately $50 \%$ of human colon tumors are GR-positive and the increased GR expression in colorectal adenocarcinoma patients is actually linked with a poor prognosis [21].

In our previous studies, we have shown that GR modulation has an impact on the colon cancer-derived CAF biology and function. Treatment with the GC dexamethasone (Dex) diminished inflammatory gene expression, and moreover, generated substantial changes in the $\mathrm{CAF}$ secretome, including suppression of expression of hepatocyte growth factor/scatter factor (HGF/SF) and tenascin C (TNC) [22,23]. $\mathrm{HGF} / \mathrm{SF}$ is a well-documented factor with mitogenic and motogenic properties on epithelial and endothelial cells, that acts via the c-Met receptor $[24,25]$. TNC is an extracellular matrix protein abundant during the wound healing process and also involved in cancer invasion via low-affinity binding to the epidermal growth factor receptor (EGFR) [26]. CAF-derived HGF and TNC were proven to be both necessary - but not sufficient on their own - to promote colon cancer cell invasion in vitro, via RhoA and Rac pathways [27]. Interestingly, both HGF and TNC were strongly downregulated in CAFs, at mRNA and protein levels, following a GC treatment. Therefore, we wanted to establish the relevance of these GC-driven changes in CAF secretomes on cancer cell proliferation, migration, and invasion, and as such, to provide a novel insight into the role of GCs in the colon cancer microenvironment.

\section{Materials and Methods}

\subsection{Cells and reagents}

HCT8/E11 human colorectal adenocarcinoma (ATCC number: CCL244) [28], in-house engineered HCT8/E11-luc cells [29], HCT116 human colon carcinoma (ATCC number: CCL-247) [30] and CT5.3hTERT human stromal colon cancer-derived CAFs [31] were cultured in DMEM (Life Technologies, Merelbeke, Belgium) supplemented with $10 \%$ fetal calf serum (Greiner bio-one, Wemmel, Belgium), $100 \mathrm{U} / \mathrm{ml}$ penicillin and $0,1 \mathrm{mg} / \mathrm{ml}$ streptomycin (Life Technologies) at $37{ }^{\circ} \mathrm{C}$ with $10 \% \mathrm{CO}_{2}$. DMEM used in experiments was serum-free or supplemented with charcoal-stripped serum (Life Technologies). The GCs dexamethasone (Dex), hydrocortisone (Hcrt), prednisolone (Pred) and fluocinolone acetonide (FA) were purchased from Sigma-Aldrich (Diegem, Belgium) and dissolved in ethanol. A selective GR modulator (SEGRM) compound A (CpdA) was prepared according to De Bosscher, et al. $[28,32]$. Recombinant murine tumor necrosis factor (TNF) $\alpha$ was prepared as described by Vanden Berghe, et al. [33] and dissolved in serum-free DMEM. Firefly D-luciferine was purchased from PerkinElmer (Zaventem, Belgium) and prepared according to the manufacturer's instructions. Human recombinant hepatocyte growth factor (hrHGF) was purchased from PromoKine (Heidelberg, Germany, cat no: c-64532), human recombinant tenascin C (hrTNC) was purchased from R\&D Systems (Abingdon, UK, cat no: 3358-TC-50) and both were resuspended in PBS.

\subsection{Conditioned medium preparation}

Conditioned medium (CM) was prepared according to previous protocols [34]. Briefly, supernatants were collected from $10 \times 10^{6}$ CT5.3hTERT CAFs, which were cultured for $48 \mathrm{~h}$ in serum-free DMEM and treated with solvent (ethanol), Dex or, optionally, with Hcrt, Pred, FA or a SEGRM CpdA in concentrations listed in Table 1. Subsequently, $\mathrm{CM}$ was 10 -fold concentrated with centrifugal filter tubes with a $3 \mathrm{kDa}$ cut-off (Amicon Ultra, Merck Millipore, Darmstadt, Germany) and filter-sterilized prior to storage at $-20^{\circ} \mathrm{C}$.

\subsection{Cell lysis and western blot analyses}

Cells were collected from HCT8/E11, HCT116 and/or CT5.3hTERT cultures and subsequently washed with PBS. Protein lysates were made using TOTEX buffer (20 mM Hepes/KOH pH 7.9; $0.35 \mathrm{M} \mathrm{NaCl} ; 20 \%$ glycerol; $1 \% \mathrm{NP} 40 ; 1 \mathrm{mM} \mathrm{MgCl} 2 ; 0.5 \mathrm{mM}$ EDTA; $0.1 \mathrm{mM}$ EGTA; $2 \mathrm{mM}$ pefabloc; $10 \mu \mathrm{g} / \mathrm{ml}$ aprotinin). Protein concentration was determined via the Lowry method [28]. Alternatively, 10-fold concentrated conditioned medium from CAFs treated with solvent or Dex $(1 \mu \mathrm{M})$ for $48 \mathrm{~h}$, was prepared for western blot analysis using SDS sample buffer (50 mM Tris pH6.8; 2\% SDS; 10\% glycerol; bromophenol blue, $100 \mathrm{mM}$ DTT).

Samples were subjected to SDS-PAGE followed by a standard Western Blot protocol, as described by Santa Cruz (Santa Cruz Biotechnology, CA, USA). As primary antibodies, we used anti-GR (H-

Table 1

List of compounds used to incubate CT5.3hTERT CAFs and subsequent preparation of conditioned media. The concomitant ethanol concentrations are identical in all conditions.

\begin{tabular}{lll}
\hline Compound & Concentration & Abbreviation used for the CM \\
\hline Ethanol & $0.1 \%$ & $\mathrm{CM}^{\mathrm{CTRL}}$ \\
Dexamethasone & $1 \mu \mathrm{M}$ & $\mathrm{CM}^{\mathrm{DEX}}$ \\
Hydrocortisone & $1 \mu \mathrm{M}$ & $\mathrm{CM}^{\mathrm{HCRT}}$ \\
Prednisolone & $1 \mu \mathrm{M}$ & $\mathrm{CM}^{\mathrm{PRED}}$ \\
Fluocinolone acetonide & $1 \mu \mathrm{M}$ & $\mathrm{CM}^{\mathrm{FA}}$ \\
Compound A & $10 \mu \mathrm{M}$ & $\mathrm{CM}^{\mathrm{CPDA}}$ \\
\hline
\end{tabular}


300) (1/1000, Santa Cruz Biotechnology, cat no: sc-8992), anti-tubulin (1/4000, Sigma-Aldrich, cat no: T5168) and anti-human MMP-2 (1/ 500, R\&D Systems, cat no: AF902). We used species-specific HRP-linked secondary antibodies anti-mouse, anti-rabbit (GE Healthcare, Diegem, Belgium, cat no: NA931V, NA934V) and anti-goat (Santa Cruz Biotechnology, cat no: sc-2020). For visualization of the results we used ECL solution (Thermo Scientific, Gent, Belgium) and X-Ray films (GE Healthcare) or alternatively WesternBright Quantum HRP substrate (Advansta, CA, USA) and a ProXima imaging platform 2850 with ProXima AQ-4 software (Isogen Life Science, De Meern, The Netherlands). Quantification of western blot results was performed using ImageJ software [35] according to previous protocols [36].

\subsection{RNA isolation and $R T-q P C R$}

HCT8/E11, HCT116 and CT5.3hTERT cells were collected and total RNA was isolated. Alternatively, HCT8/E11 cells were first induced with solvent, Dex $(1 \mu \mathrm{M})$ or a SEGRM CpdA $(10 \mu \mathrm{M})$ for $1 \mathrm{~h}$ and then cotreated with TNF $\alpha$ or equivalent volume of DMEM for another $5 \mathrm{~h}$, before total RNA was isolated. We used TRIzol reagent (Life Technologies) to isolate the total RNA from these cells, which was subsequently followed by reverse transcription (RT), performed with an iScript kit (Bio-Rad), and quantitative PCR (qPCR) using Lightcycler 480 SYBRGreen I Master reagents (Roche Diagnostics, Rotkreuz, Switzerland), all according to the manufacturers' instructions. We performed APCR reactions in triplicates using the Lightcycler ${ }^{\circledR} 480$ system (Roche Diagnostics) and the following protocol: A) initial denaturation $95^{\circ} \mathrm{C}, 5^{\prime}$; B) 40 cycles of denaturation $95^{\circ} \mathrm{C}, 15^{\prime \prime}$, annealing and elongation $60^{\circ} \mathrm{C}, 45^{\prime \prime}$. Primer sequences are available in the Supplementary data (Supplementary Table 1). Further, results were normalized to the results obtained for the respective geometric mean of 3 housekeeping genes (GAPDH, PPIB, 36B4). Final results are displayed as relative mRNA expression, in which the solvent control condition was set as 1 and all other conditions were recalculated accordingly.

\subsection{Gelatin zymography}

Conditioned medium from CT5.3hTERT cells treated with solvent or Dex $(1 \mu \mathrm{M})$ for $48 \mathrm{~h}$ was 10 -fold concentrated and applied to the zymography protocol as described [24]. Briefly, conditioned medium samples were subjected to SDS-PAGE using $10 \%$ polyacrylamid- $0.1 \%$ gelatin gels. Next, gels were incubated in renaturing solution $(2.5 \%$ Triton-X) for $30 \mathrm{~min}$, then washed twice with $\mathrm{dH}_{2} \mathrm{O}$ and incubated at $37^{\circ} \mathrm{C}$ in a developing buffer ( $50 \mathrm{mM}$ Tris- $\mathrm{HCl} \mathrm{pH} \mathrm{7.8,} 0.2 \mathrm{M} \mathrm{NaCl}, 5 \mathrm{mM}$ $\mathrm{CaCl}_{2}$ ) overnight. Subsequently, gels were stained with Coomassie Brilliant Blue R-250 (Bio-Rad, Temse, Belgium) for $1 \mathrm{~h}$ and then destained with destaining solution (10\% methanol, 5\% acetic acid). Quantification of zymogram results was performed with ImageJ software as explained earlier [37]. As this particular assay may not represent the actual state of MMPs released by cells, due to possible inactivation via noncovalent binding with tissue inhibitors of MMPs (TIMPs), these results are expressed as"potential enzyme activity".

\subsection{Cell proliferation assays}

To assess proliferation of HCT8/E11-luc cells we performed a coculture assay and assays using CM from CAFs, based on previous protocols [36]. In a co-culture assay CT5.3hTERT cells were seeded in 24well plates together with HCT8/E11-luc cells at a 10:1 ratio and subjected to solvent or Dex $(1 \mu \mathrm{M})$ incubation. After a $72 \mathrm{~h}$ incubation, Dluciferine $(150 \mu \mathrm{g} / \mathrm{ml})$ was added to the wells and luciferase activity was measured with the In Vivo Imaging System Lumina II (IVIS ${ }^{\circledast}$, Caliper Life Science, Hopkinton, MA, USA). Similarly, HCT8/E11-luc cells were seeded in 24-well plates $\left(10^{4} /\right.$ well) and after $24 \mathrm{~h}$ cells were treated with DMEM, CM ${ }^{\mathrm{CTRL}}$ or $\mathrm{CM}^{\mathrm{DEX}}$. D-luciferine $(150 \mu \mathrm{g} / \mathrm{ml})$ was added to the wells $72 \mathrm{~h}$ post treatment and bioluminescence was measured using the IVIS. Results were analyzed via Living Image ${ }^{\circledR}$ software (Caliper Life Science).

Additionally, we performed a sulforhodamine-B (SRB) test, as described previously [30] using the parental cell line HCT8/E11. Briefly, cells were seeded in 96-well plates $\left(5 \times 10^{3} /\right.$ well $)$ and treated with DMEM, $\mathrm{CM}^{\mathrm{CTRL}}$ or $\mathrm{CM}^{\mathrm{DEX}}$ for selected time points ( $24 \mathrm{~h}, 48 \mathrm{~h}$ and $72 \mathrm{~h}$ ). Following fixing, staining and washing steps, plates were scanned using a Paradigm ${ }^{\mathrm{TM}}$ Detection Platform (Beckman Coulter ${ }^{\circ}$, Krefeld, Germany) with SoftMax Pro 6.1 software. Results are expressed in a scale, where the untreated post treatment condition at $72 \mathrm{~h}$ was set at 1 and all other conditions were recalculated accordingly.

\subsection{Cell morphology assay}

The cell morphology assays on collagen were performed as described by De Wever et al. [38]. Briefly, single cell suspensions of $7 \times$ $10^{4}$ HCT8/E11 were seeded in 6-well plates, or alternatively, $1.2 \times 10^{4}$ cells were seeded in 24-well plates, all on a layer of type I collagen (derived from rat tail; $1 \mathrm{mg} / \mathrm{ml}$; Santa Cruz Biotechnology). Cells were treated with DMEM or with CM from CAFs, as indicated in the figure legends. Cell morphology was observed $24 \mathrm{~h}$ post treatment under a phase-contrast microscope (Leica DMI3000B with LAS4.1 software) and digital images from 10 to 15 microscopic fields ( $20 \mathrm{x}$ magnifications) were taken for further evaluation. Cells with stretched and round morphology were counted and the results per microscopic field are expressed as a relative cell stretch index.

\subsection{Migration assay}

HCT8/E11 cell migration was assessed using a Transwell system. Cells were seeded in serum-free DMEM on Transwell inserts $\left(5 \times 10^{4}\right.$ cells/insert) with $8.0 \mu \mathrm{m}$ pores (Corning Inc., Lasne, Belgium, cat no: 3422 ) and left to migrate through the membrane for $24 \mathrm{~h}$ towards serum-free DMEM, $\mathrm{CM}^{\mathrm{CTRL}}$ or $\mathrm{CM}^{\mathrm{DEX}}$, which was applied in the lower compartments of the Transwell system. After $24 \mathrm{~h}$ inserts were removed and the inside parts of these inserts were gently wiped with cotton swabs to remove cells which did not migrate. Next, the membranes were fixed with ice-cold methanol and washed 3 times for $5 \mathrm{~min}$ in PBS. Membranes were then stained with DAPI $(0.4 \mu \mathrm{g} / \mathrm{ml})$, washed with PBS and subsequently mounted on microscope glasses. Membranes were observed under a fluorescence microscope (Zeiss Axiovert $200 \mathrm{M}$, Carl Zeiss, Micro-Imaging, Heidelberg, Germany), which enabled counting the cells that migrated through the porous membrane. Cells were counted per microscopic field (10 $\times$ magnification), and 10 fields per condition were assessed.

\subsection{Adhesion assays}

Cell-to-cell adhesion assays between CAFs and HCT8/E11 cells were performed as described [39]. CT5.3hTERT cells were cultured in 24well plates until confluency. Subsequently, cells were incubated with solvent or Dex $(1 \mu \mathrm{M})$ for $24 \mathrm{~h}$ prior to an additional seeding of $10^{4}$ HCT8/E11-luc cells/well. After $24 \mathrm{~h}$ of co-culturing, cells were washed twice with DMEM in order to remove the non-adherent cells. Subsequently D-luciferine $(150 \mu \mathrm{g} / \mathrm{ml})$ was added to the wells and luciferase activity was measured using the IVIS system.

HCT8/E11 cancer cells' adhesion to collagen coating was measured as described [30]. Briefly, HCT8/E11 cells (10 $/$ well) were seeded in quadruplicates in type I collagen-coated $(50 \mu \mathrm{g} / \mathrm{ml})$ E-16 plates (ACEA Biosciences, Sand Diego, CA, USA). Cells were seeded in serum-free DMEM, $\mathrm{CM}^{\mathrm{CTRL}}$ and $\mathrm{CM}^{\mathrm{DEX}}$. Cell-electrode impedance indicating cell adhesion was assessed every $5 \mathrm{~min}$ for $24 \mathrm{~h}$ using xCELLigence RTCA SP (ACEA Biosciences). Cell adhesion is reported as a relative cell index and areas under the curve (AUC) were calculated for the first $60 \mathrm{~min}$ of each treatment. 


\subsection{Chorioallantoic membrane (CAM) assay}

The chick embryo CAM assay was performed according to [40] and slightly adjusted. Briefly, fertilized eggs from a local hatchery were incubated at $37.8{ }^{\circ} \mathrm{C}$ and $50 \%$ humidity in a poultry egg incubator (RCOM 50 Digital Egg Incubator, Gyeonggi-do, South Korea). At day 3 of embryonic development, 2-3 $\mathrm{ml}$ of albumen was removed with a sterile needle in order to lower the level of the CAM. Additionally, an opening of approximately $1 \mathrm{~cm}^{2}$ was made in the eggshell in order to evaluate the embryos' state and eliminate dead or non-fertilized eggs. The window was then covered with a semipermeable polyurethane film (Suprasorb F, Lohmann \& Rauscher, Neuwied, Germany). At day 9, single cell suspensions of $10^{6}$ HCT8/E11 cancer cells together with 2.5 $\times 10^{6}$ CT5.3hTERT CAFs were seeded onto the CAM in Matrigel ${ }^{\mathrm{TM}}$ drops $(100 \mu \mathrm{l} / \mathrm{CAM})$. Cells were treated while seeding with solvent or Dex $(1 \mu \mathrm{M})$ and re-treated $48 \mathrm{~h}$ later in $20 \mu \mathrm{l}$ Matrigel drops. Five days after seeding, tumors were observed under the stereomicroscope (Leica Microsystems, Diegem, Belgium) and digital images were taken. Tumors where examined in at least 7 viable embryos per treatment condition in each of 4 repetitions of the experiment. CAM fragments containing tumors were harvested and fixed in buffered formaldehyde (4\% formaldehyde, $4 \mathrm{~g} / \mathrm{L} \mathrm{Na}{ }_{2} \mathrm{PO}_{4} \cdot \mathrm{H}_{2} \mathrm{O}, 6.5 \mathrm{~g} / \mathrm{L} \mathrm{Na}_{2} \mathrm{HPO}_{4}$ ). Subsequently, these samples were embedded in paraffin, sectioned and subjected to hematoxylin-eosin staining, as described by Sigma-Aldrich. These prepared slides were evaluated for tumor shape (sphericity) and cancer cell infiltration into the CAM's mesenchymal layer, on a scale from 1 to 5 (Supplementary Table 2).

\subsection{Statistical analyses}

We performed statistical analyses using GraphPad Prism 5.03 with the unpaired student $t$-test, Mann-Whitney test or one-way analysis of variance (ANOVA) with Tukey's multiple comparisons post-test, where applicable as indicated in the figure legends. A p-value of $p<0.05$ was considered statistically significant.

\section{Results}

\subsection{HCT8/E11 cells do not express a functional GR}

In order to investigate the role of glucocorticoid receptor (GR) modulation in CAFs and its subsequent effects on colon cancer cells, we chose a colon cancer cell line that does not express a functional GR, enabling us to research the direct influence of glucocorticoid (GC) treatment limited solely to CAFs. Western blot and qPCR analyses revealed that HCT8/E11 colon cancer cells display lack of GR at both mRNA and protein levels (Fig. 1A-B). Another colon cancer cell line, HCT116, showed a moderate expression of the receptor, both at mRNA and protein levels, as compared to colon cancer-derived CT5.3hTERT CAFs, which express relatively high levels of both GR mRNA and GR protein (Fig. 1A, B). Corresponding with its GR-deficient status, the administration of the glucocorticoid Dex $(1 \mu \mathrm{M}, 6 \mathrm{~h})$ to HCT8/E11 cells did not lead to a statistically significant upregulation of glucocorticoidinducible leucine zipper (GILZ), a gene known to be highly expressed following GC treatment [41] (Fig. 1C). In HCT116 cells, GILZ was 5.5fold upregulated due to Dex treatment while in CT5.3hTERT cells we observed an average 70-fold GILZ mRNA upregulation. Additional to the lack of GR transactivation in HCT8/E11 cells, these cells also did not display GR-mediated transrepression properties (Supplementary Fig. 1A-B). The treatment with TNF $\alpha$ led to an upregulation of NFKBdriven pro-inflammatory molecules, namely ICAM and MCP-1 in HCT8/ E11 cells. However, a co-treatment with Dex did not lead to a suppression of expression of these molecules, in contrast to CT5.3hTERT cells, where this suppression was well pronounced [42]. The selective GR modulator (SEGRM) compound A (CpdA), a non-steroidal plantderived molecule, yet able to modulate GR favoring its transrepressive actions [24], displayed a similar pattern as Dex. These combined results point to a lack of both GR transactivation and GR transrepression activities in the GR-deficient HCT8/E11 cells.

\subsection{Secretion of MMP-2 by CAFs is affected by Dex-treatment}

MMP-2 belongs to the family of matrix metalloproteinases and has been studied as one of the biomarkers of colorectal cancer [24,33]. In order to investigate MMP-2's presence in CAF secretomes, we performed western blot analyses, which showed that MMP-2 levels are decreased in the conditioned medium of these cells following $48 \mathrm{~h}$ Dex exposure (Fig. 2A-B). An MMP-2 activity assay, gelatin zymography, revealed that the majority of MMP-2 was secreted in an inactive form (pro-enzyme), as pro-MMP-2 (Fig. 2C). The potential activity of the MMP-2 pro-enzyme and of the MMP-2 active form decreased in samples obtained from Dex-treated cells, $\mathrm{CM}^{\mathrm{DEX}}$, compared to CM ${ }^{\mathrm{CTRL}}$ (Fig. 2CD), which is in line with the protein expression status. However, only the difference in pro-enzyme potential activity obtained statistical significance. Although MMP-9 could not be visualized via Western blot analyses (data not shown), pro-MMP-9 could be visualized via zymography at very low signal compared to MMP-2. Pro-MMP-9's potential activity was also decreased in $\mathrm{CM}^{\mathrm{DEX}}$ (Fig. 2E).

\subsection{Indirect impact of Dex treatment on HCT8/E11 through co-culture with} CAFs affects proliferation but not adhesion of HCT8/E11 cells

To investigate whether Dex treatment could have a CAF-mediated effect on HCT8/E11 we performed a cell proliferation and cell-to-cell adhesion assay in a co-culture system. In the proliferation assay (Fig. 3A), HCT8/E11-luc cells cultured together with CT5.3hTERT CAFs in a 1:10 ratio, displayed growth inhibition in the presence of Dex $(1 \mu \mathrm{M}, 72 \mathrm{~h})$ compared with solvent control-treated cells. An adhesion assay using a CAF confluent culture showed that pre-treatment of these cells with Dex $(1 \mu \mathrm{M}, 24 \mathrm{~h})$ did not affect HCT8/E11-luc adhesion to CAFs and their secreted matrix (Fig. 3B) in comparison to solvent control-treated cells.

\subsection{HCT8/E11 cell proliferation, morphology, and motility are changed due to exposure to $C M^{D E X}$ compared to $C M^{C T R L}$}

To assess whether the growth-inhibitory effects of Dex-treated CAFs originate from changes in the CAF secretome, we performed experiments using CAF-derived conditioned medium $\left(\mathrm{CM}^{\mathrm{CTRL}}\right)$ and $\mathrm{CM}$ from Dex-treated CAFs $\left(\mathrm{CM}^{\mathrm{DEX}}\right)$. Via cell viability and metabolic activity assays (MTT), we observed that neither $\mathrm{CM}^{\mathrm{CTRL}}$ nor $\mathrm{CM}^{\mathrm{DEX}}$ impaired cell survival tested in a confluent culture of HCT8/E11 after $72 \mathrm{~h}$ of treatment (Supplementary Fig. 2). In a cell proliferation experiment with HCT8/E11-luc cells (Fig. 4A), we observed that both CM ${ }^{\text {CTRL }}$ and $\mathrm{CM}^{\mathrm{DEX}}$ promoted colon cancer cell growth, compared to the control treatment with DMEM. However, $\mathrm{CM}^{\mathrm{DEX}}$ had a significantly weaker impact than $\mathrm{CM}^{\mathrm{CTRL}}$ on HCT8/E11-luc growth after $72 \mathrm{~h}$ of incubation. These results are consistent with data obtained from an SRB assay in which proliferation of the parental HCT8/E11 cell line was assessed in the presence of CM from CAFs (Fig. 4B). Also in this situation, $72 \mathrm{~h}$ incubation with CM promoted cell growth compared to DMEM, and effects of $\mathrm{CM}^{\mathrm{DEX}}$ were less pronounced than those of $\mathrm{CM}^{\mathrm{CTRL}}$.

Changes in cell morphology into a stretched, elongated shape are associated with epithelial-to-mesenchymal transition (EMT) and a subsequent cell invasion [43]. In an in vitro cell morphology assay on collagen, HCT8/E11 cells treated with $\mathrm{CM}^{\mathrm{CTRL}}$ adopted a stretched morphotype, characteristic for invasive cells (Fig. 4C, Supplementary Fig. 3). Treatment with $\mathrm{CM}^{\mathrm{DEX}}$ resulted in a significantly diminished number of cells with such stretched morphotype. Moreover, cell morphology effects obtained with $\mathrm{CM}^{\mathrm{DEX}}$ were also observed with $\mathrm{CM}$ from CAFs treated with other GCs, namely FA, Pred and Hcrt (Supplementary Fig. 4A). Furthermore, although unlikely due to the GR-defective status 
A.

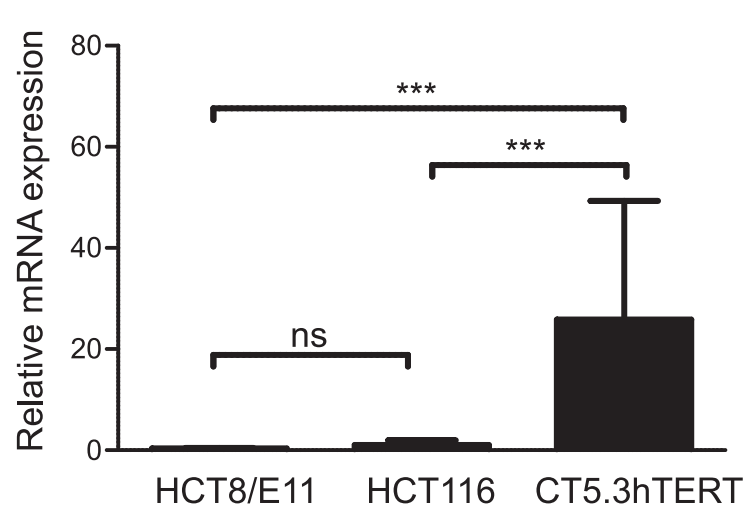

B.

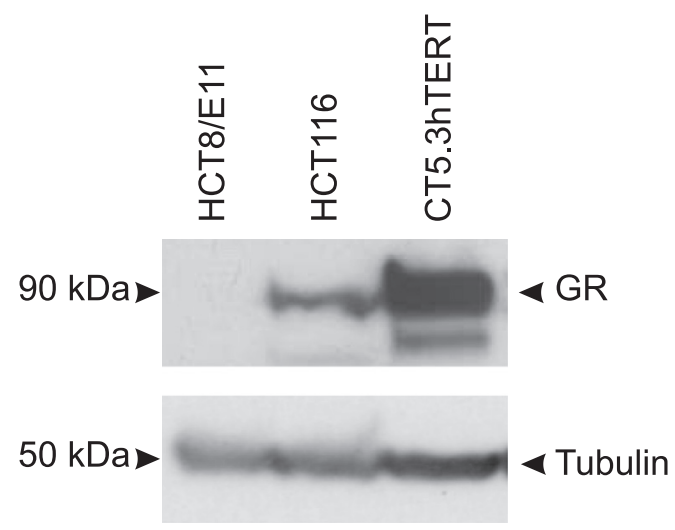

C.

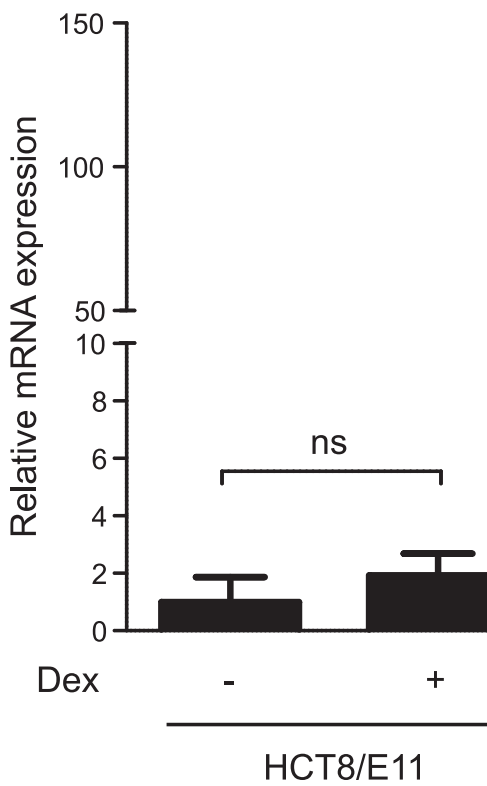

GILZ 
A.

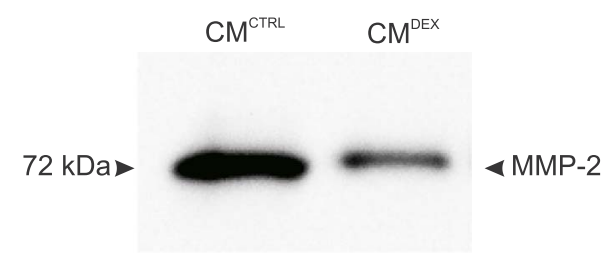

C.
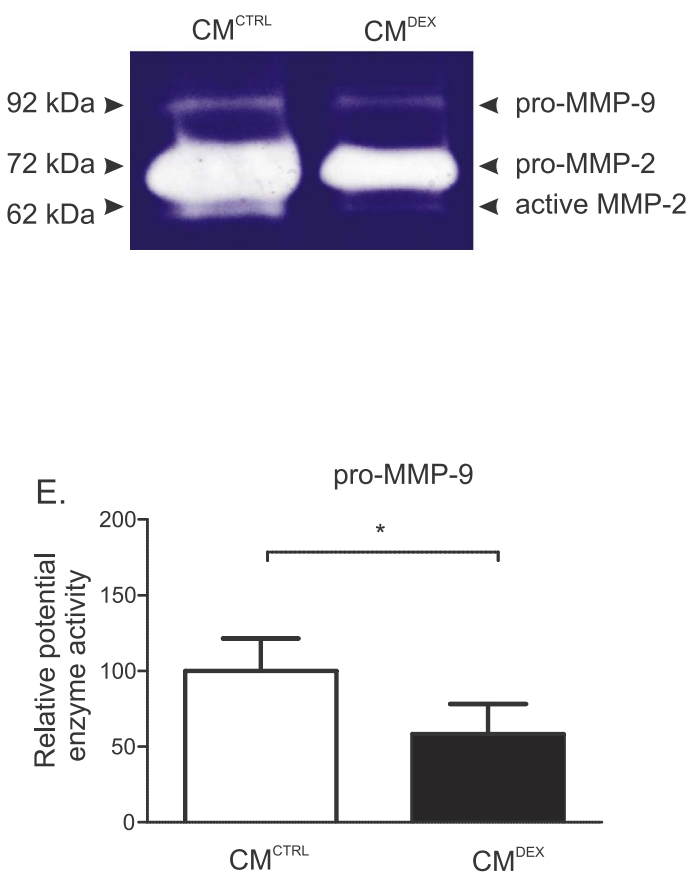

B.

MMP-2

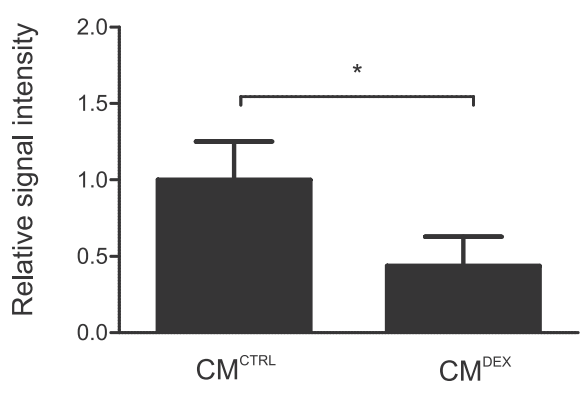

D.

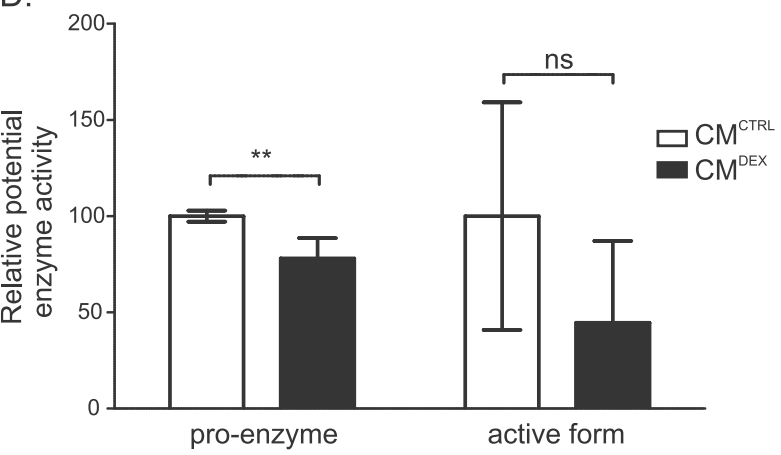

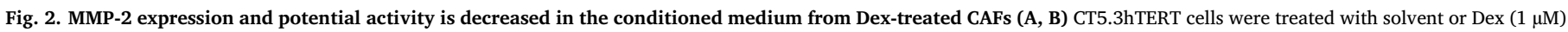

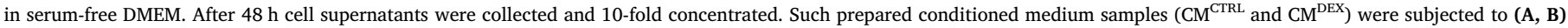

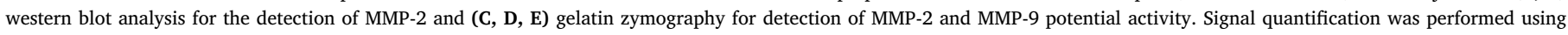

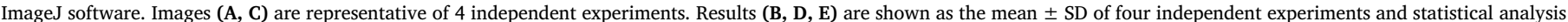
was performed using an unpaired $t$-test. ns: not significant, ${ }^{* *}$ : $\mathrm{p}<0.01,{ }^{*}: \mathrm{p}<0.05$.

inserts (Transwell), we observed that the presence of $\mathrm{CM}^{\mathrm{CTRL}}$ below the insert favored HCT8/E11 cell migration through the membrane, compared with a DMEM control (Fig. 4D). $\mathrm{CM}^{\mathrm{DEX}}$, however, induced colon cancer cell migration slightly stronger compared to $\mathrm{CM}^{\mathrm{CTRL}}$.

Similarly to the co-culture experiments results, CAF-derived CM did not affect HCT8/E11 cell adhesion to a type I collagen coating (Fig. 4E), which was measured via cell impedance (xCELLigence). Analysis of the area under the curve (AUC; Fig. 4F) indicated that HCT8/E11 cells adhered to the collagen coating evenly, disregarding the treatment with CAF-derived $\mathrm{CM}^{\mathrm{CTRL}}$ or $\mathrm{CM}^{\mathrm{DEX}}$.

In conclusion, CM from Dex-treated CAFs displayed diminished proinvasive and pro-growth potential, but had stronger pro-migratory properties on HCT8/E11 colon cancer cells, as compared to CM from the control CAFs.

\subsection{Dex treatment inhibits tumor formation in vivo}

The in vivo chorioallantoic membrane (CAM) assay is widely used as a model for tumor development, invasion, and angiogenesis [8]. HCT8/E11 cells seeded together with CT5.3hTERT CAFs in a drop of Matrigel were able to form tumors (Fig. 5A). Application of Dex (1 $\mu \mathrm{M})$ for 5 days affected tumor shape, resulting in less spherical tumors (Fig. 5B). Moreover, in Dex-treated tumors a significant inhibition of cancer cell infiltration into CAM's mesenchymal layer was observed (Fig. 5C).

\section{Discussion}

Recruited by cancer cells at the invasion front, stromal myofibroblasts, also known as cancer-associated fibroblasts (CAFs), are proven to promote cancer progression [45]. Recent findings show that radiotherapy and chemotherapy affect cancer microenvironments, leading to the release of certain stromal-derived cancer-promoting factors and subsequent therapy resistance [10]. In the current study, we have shown that glucocorticoid (GC)-treated CAFs, besides previously described diminished pro-angiogenic properties [12,46], have additionally an impaired ability to promote cancer cell growth and invasion and an increased ability to promote cell migrattion, as compared to the non-treated CAFs. These results suggest that GCs could be helpful in neutralizing the negative effects of activated stroma and possibly also counteract therapy resistance, including the environment-mediated drug resistance (EMDR). 
A.

$$
\begin{gathered}
\text { co-cultures HCT8/E11-luc } \\
\text { with CAFs }
\end{gathered}
$$

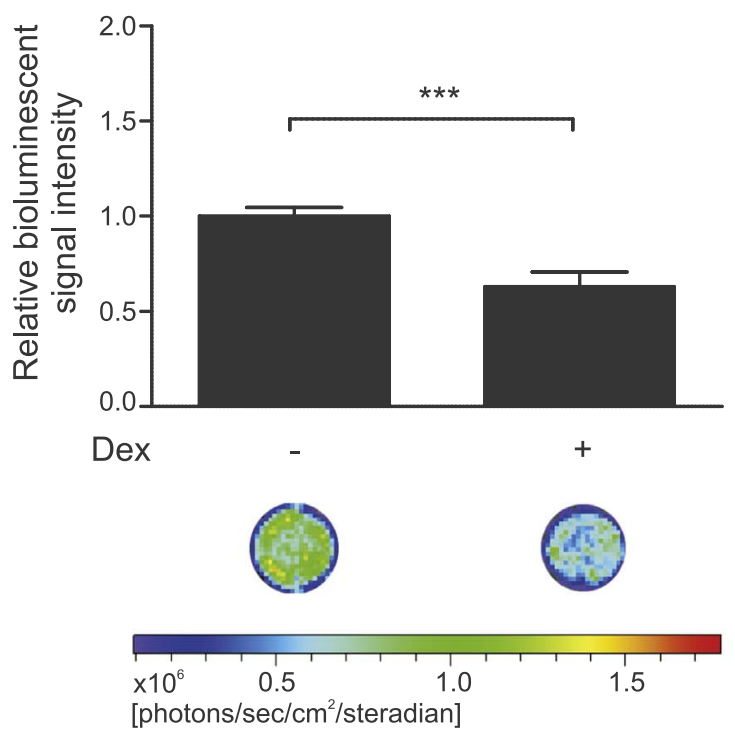

B.
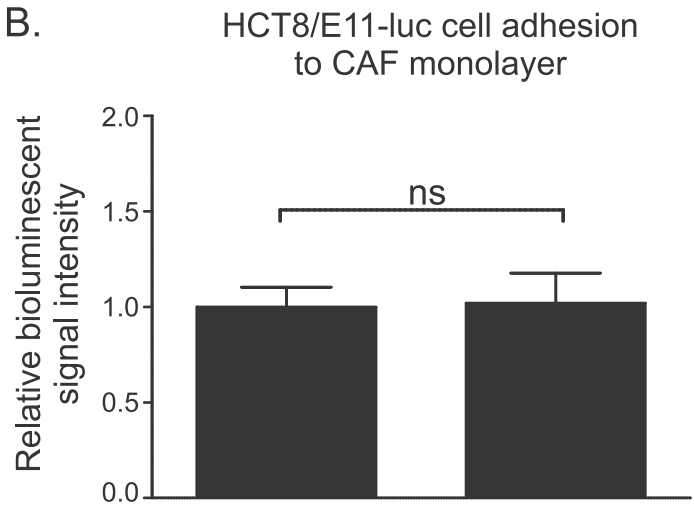

Dex

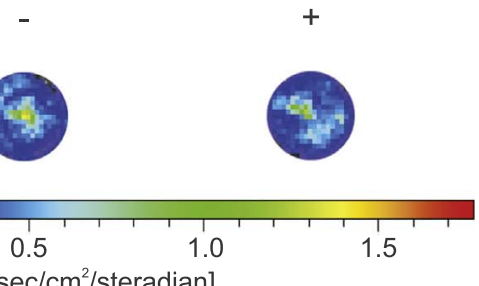

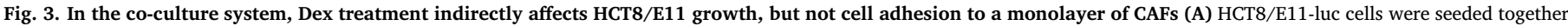

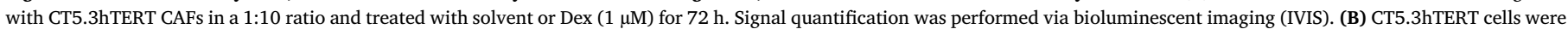

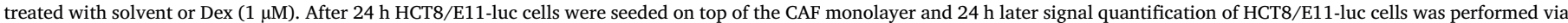

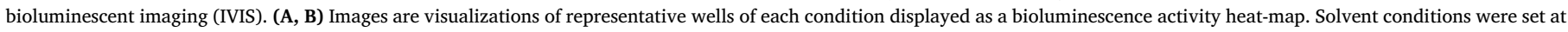

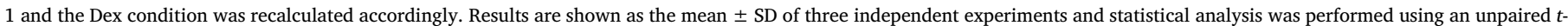
test. ns: not significant, ${ }^{* * *}: \mathrm{p}<0.001$.

As previously reported, following a GC treatment, CAFs display a decreased expression and subsequent secretion of tenascin C (TNC), hepatocyte growth factor/scatter factor (HGF/SF), and several other factors associated with cancer proliferation, invasion and/or angiogenesis [25]. Furthermore, the reduced amounts of secreted TNC and HGF in the condition medium from Dexamethasone (Dex)-treated CAFs $\left(\mathrm{CM}^{\mathrm{DEX}}\right)$ correspond with decreased pro-invasive potential of $\mathrm{CM}^{\mathrm{DEX}}$, reflected by a diminished number of HCT8/E11 colon cancer cells with acquired stretched morphotype on type I collagen [24,25]. Although our data and literature support give a strong argument that GC-mediated decrease of TNC and HGF in CAF-derived CM could be responsible for diminished pro-invasive effects of the $\mathrm{CM}^{\mathrm{DEX}}$, the addition of recombinant TNC and HGF proteins to $\mathrm{CM}^{\mathrm{DEX}}$ did not restore the stretched morphotype of HCT8/E11 cells up to the levels obtained with CM from solvent-treated CAFs ( $\left.\mathrm{CM}^{\mathrm{CTRL}}\right)$. These data suggest that $\mathrm{HGF}$ and TNC are not sole players in the observed phenomena and point to the co-involvement of other factor(s) sensitive to GC treatment. In our current study, we extended these findings by showing that other molecules important for cancer progression, namely the extracellular matrix (ECM) proteinases MMP-2 and MMP-9 are affected in CAF CM after treatment with Dex, resulting in reduced expression level or potential activity. MMP-2 is known to affect cell morphology and motility via cleavage of adhesion molecules $[24,28]$ and via proteolytic degradation of matrix proteins, limiting cell-surface interactions [47]. In line, MMP2, but not MMP-9, was previously reported to cleave type I collagen [48]. Table 2 lists reported to date GC-sensitive factors secreted by colon cancer-derived CAFs and the corresponding GC-mediated effects.

Importantly, cell migration and invasion mechanisms, inherent processes during cancer progression, depend greatly on the cell type and surrounding tissue environment [49]. Cells with a round (amoeboid) morphology, migrate by adapting their shape, which enables them to squeeze through gaps or narrow spaces [50]. We observed that this amoeboid-like phenotype is preferred when HCT8/E11 colon cancer cells are treated with $\mathrm{CM}^{\mathrm{DEX}}$. On the other hand, a spindleshaped, elongated morphotype, which relies on actin cytoskeleton polarization, formation of extensions, and intensified protease-dependent
ECM degradation, forms the well-described reaction of HCT8/E11 cells to treatment with the $\mathrm{CM}^{\mathrm{CTRL}}$ [50]. Although both types of cell migration are common and essential during cancer progression, the single amoeboid cells form the fastest migratory phenotype, thus, considering the role of cell motility in metastasis formation, the accelerated cancer cell migration induced by $\mathrm{CM}^{\mathrm{DEX}}$ could promote cancer cell dissemination $[28,39,50]$. Although previous studies showed that direct effects of GCs on GR-responsive colon cancer cells caused inhibition of cell migration and invasion [50,51], the indirect effects via CAFs could counteract this motility inhibition, or even enhance it in cancer cells lacking a functional GR. Nevertheless, in the more complex, in vivo chick chorioallantoic membrane (CAM) model, overall effects of GC treatment seemed to inhibit cancer cell progression. HCT8/E11 colon cancer cells applied together with CT5.3hTERT CAFs formed spherical, invasive tumors, but the treatment with Dex led to a decreased cancer cell infiltration into the CAM's mesenchymal layer, as well as to strongly reduced tumor sphericity. Lack of a functional GR in cancer cells suggests that Dex-induced growth inhibition and impaired invasion originate from the added CAFs, which upon Dex treatment secrete a modified cocktail of factors, resulting in inadequate growth- and invasionstimulatory signals compared to the solvent-treated CAFs. Although these results seem promising, testing metastasis formation in the CAM model is impossible, therefore, xenograft mouse models would be more suitable to evaluate the long-term effects of GC treatment on colon cancer cells invasion and migration.

Our model of GR-deficient HCT8/E11 cancer cells allowed us to limit GC-mediated effects to CAFs (in vitro) and other stromal cells (in vivo). However, the indirect effects of GCs via CAFs on GR-responsive cancers must certainly also be taken into account. Importantly, the recent studies in various cancer cell lines, surgical resections and xenografts revealed GC-mediated protection of cancer cells against the cytotoxic therapies. The mechanism behind this therapy resistance was linked to GC-driven, most probably GR-mediated protection from apoptosis [52,53]. Nevertheless, the beneficial aspects of GC-treatment in various cancer cell types were also reported. In the glioblastoma cells, Dex decreased MMP-2 secretion and invasiveness of these cells via 

A.
HCT8/E11-luc cell growth in presence of CM

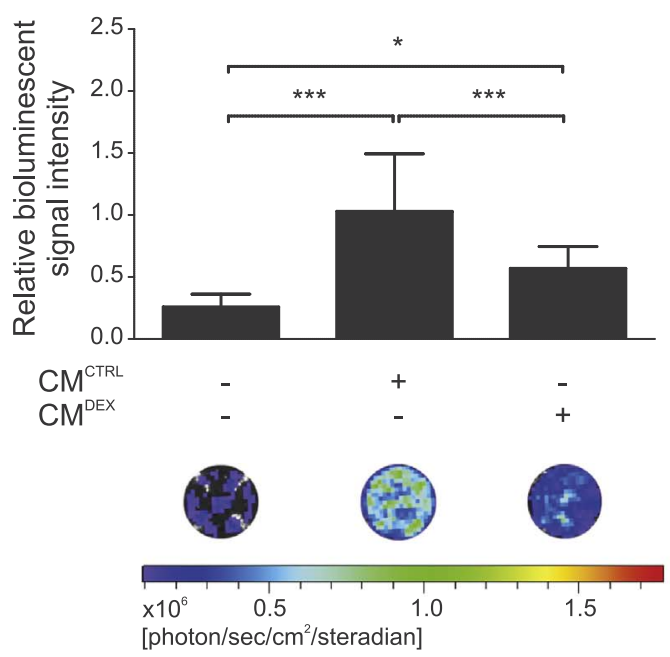

B.

HCT8/E11 cell proliferation

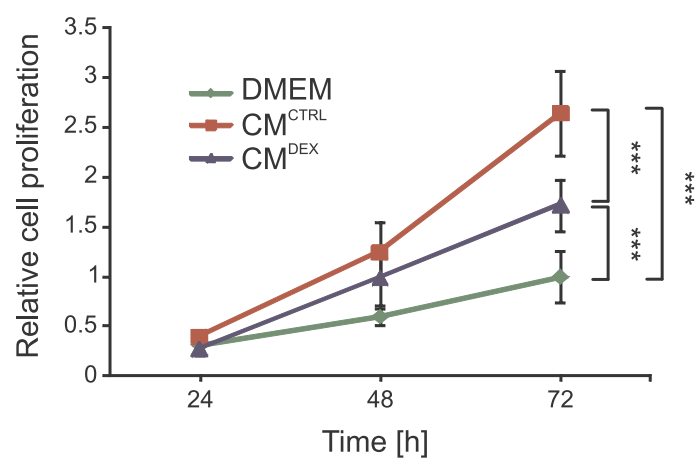

C.

HCT8/E11 cell morphology assay

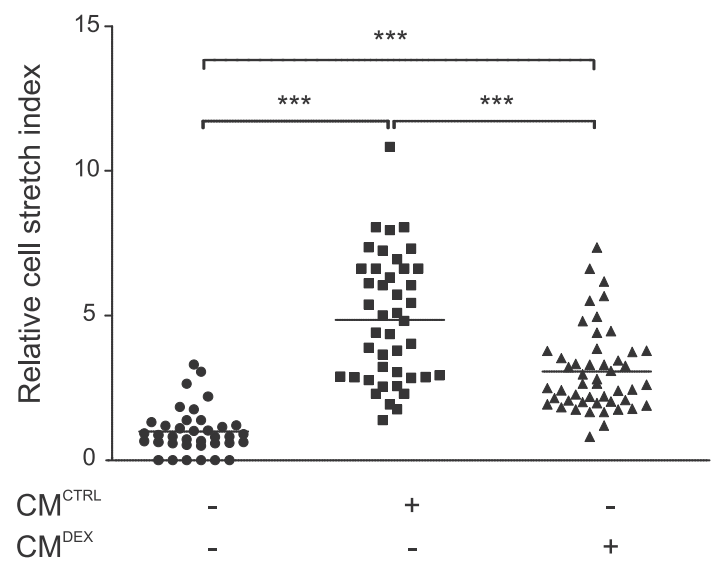

D.

HCT8/E11 cell migration
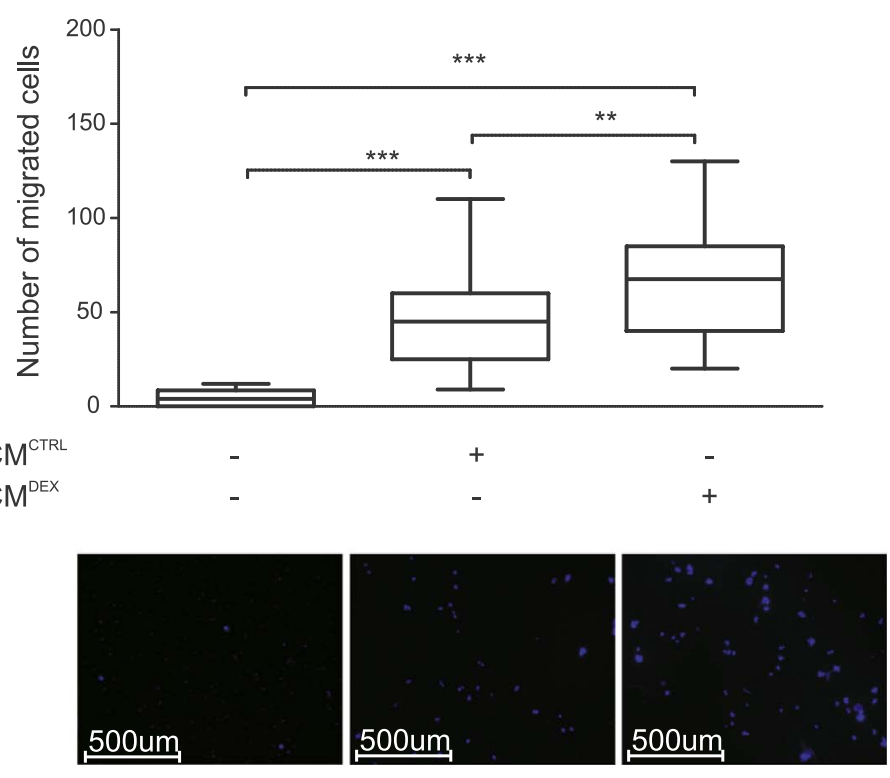

E.

HCT8/E11 adhesion to collagen coating

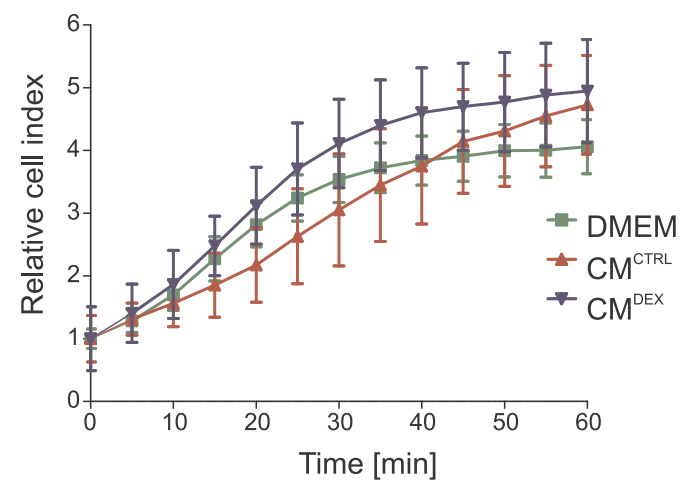

F. HCT8/E11 adhesion to collagen coating

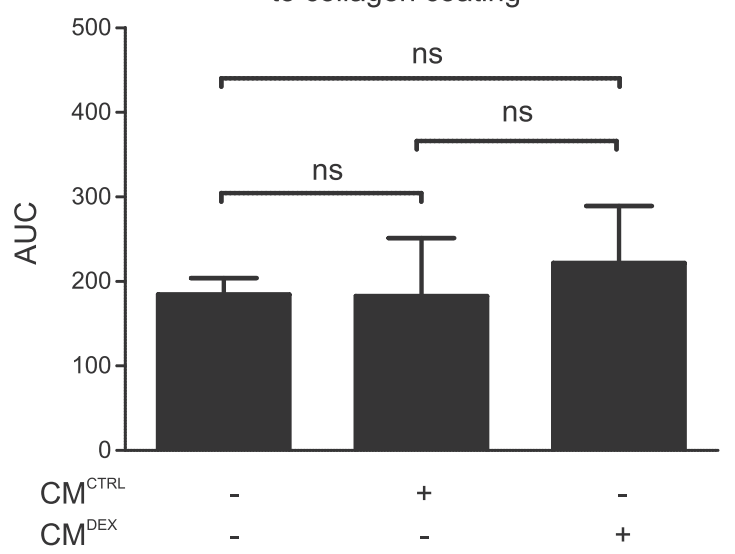




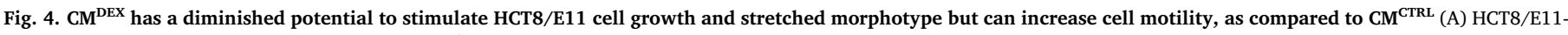

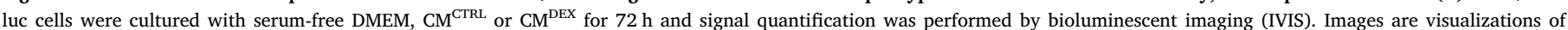

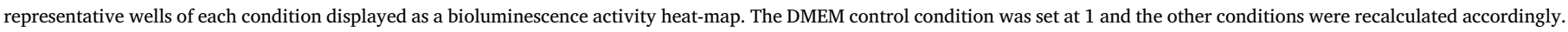

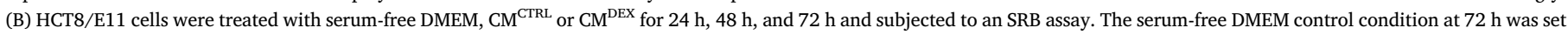

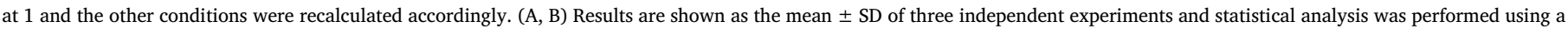

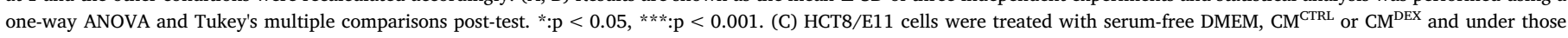

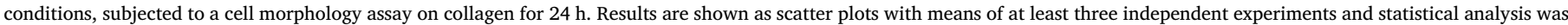

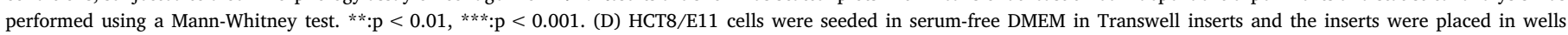

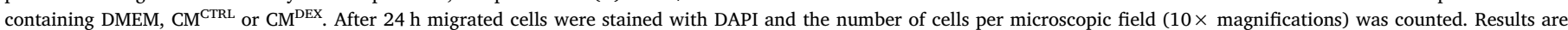

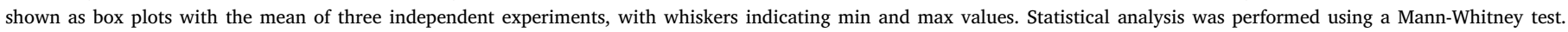

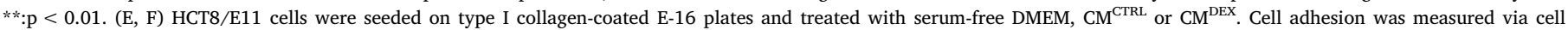

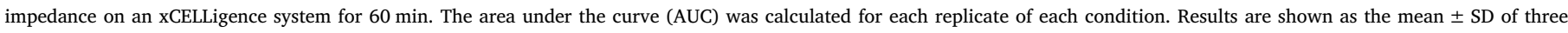
independent experiments and statistical analysis was performed on AUC using a one-way ANOVA and Tukey's multiple comparisons post-test. *:p $<0.05$, ***:p $<0.001$.

an MKP-1-mediated mechanism [54]. Similar anti-invasive properties of GC treatment were observed in bladder cancer cells and were accompanied by reduced expression of MMP-2, MMP-9, IL-6 and VEGF. Although the anti-apoptotic properties of GCs were also noted in case of these cells, in the in vivo model GC-treated tumors were in general less aggressive [55]. Moreover, in two recent studies GCs were shown to counteract TGF $\beta$ - and hypoxia-induced EMT in colon cancer cells [56]. Therefore, it seems that depending on the target cells, GCs can have different effects ranging from detrimental to positive, which points to the importance of an individual approach in planning cancer treatment.

In conclusion, our findings show that GCs, besides their present role during cancer therapy, might have an additional beneficial effect in colon cancer treatment indirectly via their impact on the activated stroma. GCs could neutralize the negative, pro-aggressive effects of CAFs on cancer cells, by modulating factors secreted by these cells.

A.

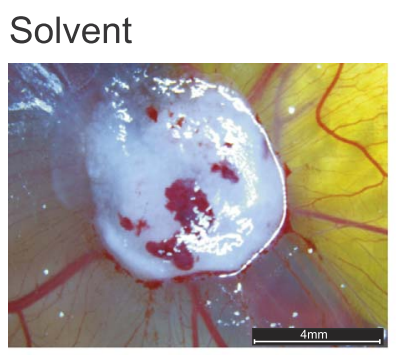

\section{Dex}
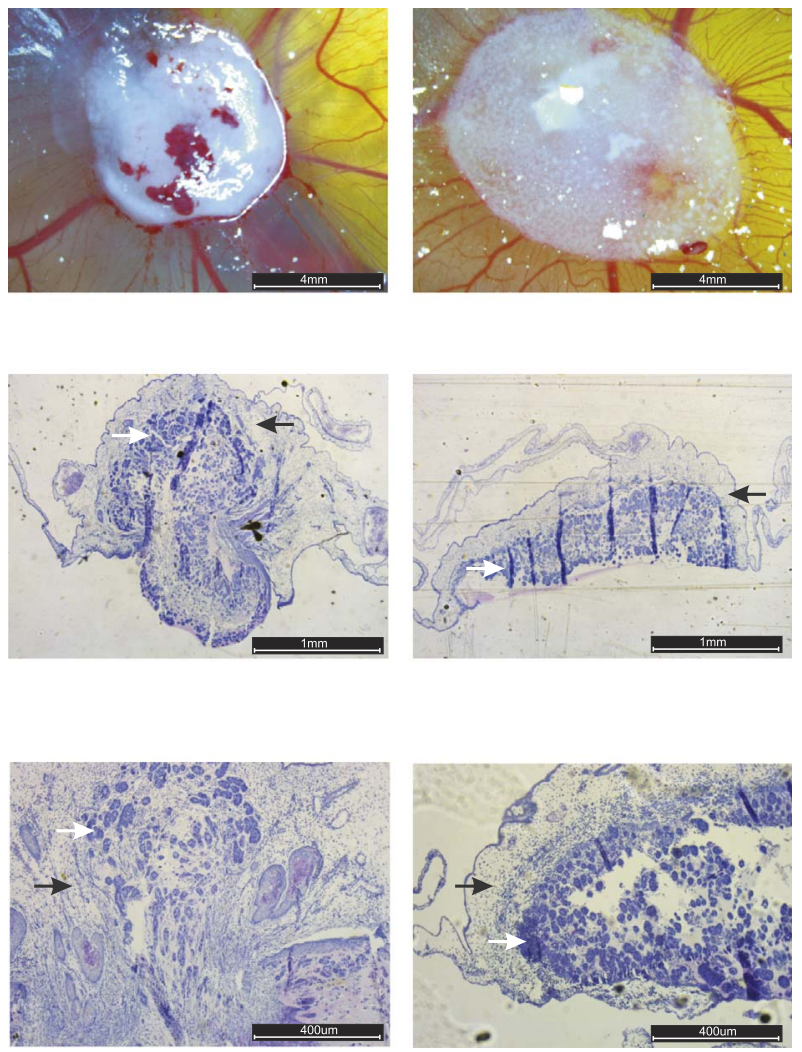

Table 2

List of GC-sensitive factors detected in colon cancer-derived CAFs' secretome in current and previous studies (c.s. - current study).

\begin{tabular}{ll}
\hline Factor & GC-mediated effects \\
\hline Angiogenin & Increased mRNA and protein levels [52,53] \\
ANGPTL-2 & Decreased mRNA and protein levels [44] \\
HGF/SF & Decreased mRNA and protein levels [44] \\
MMP-2 & Decreased protein levels and potential \\
& activity [c.s.] \\
MMP-9 & Decreased potential activity [c.s.] \\
Prostaglandins $\left(\mathrm{PGF}_{2 \alpha}, \mathrm{PGI}_{2}, \mathrm{PGE}_{2}\right)$ & Decreased concentration [24] \\
Tenascin C & Decreased mRNA and protein levels [44] \\
TGF $\beta$ & Decreased mRNA and protein levels [24] \\
uPa & Decreased mRNA and protein levels [24] \\
\hline
\end{tabular}

B.

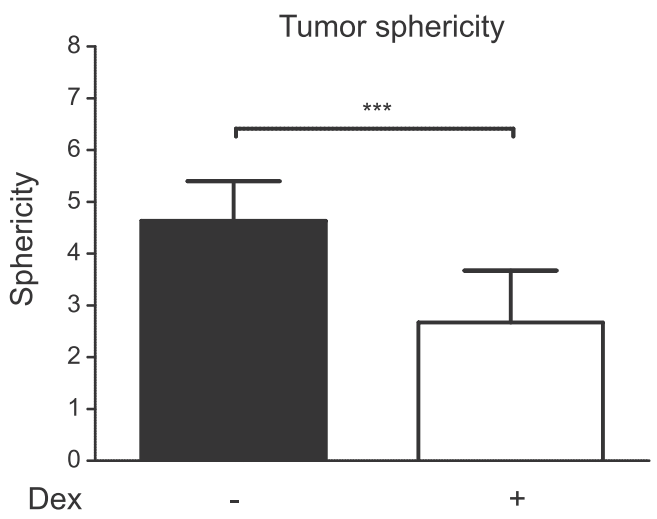

C.

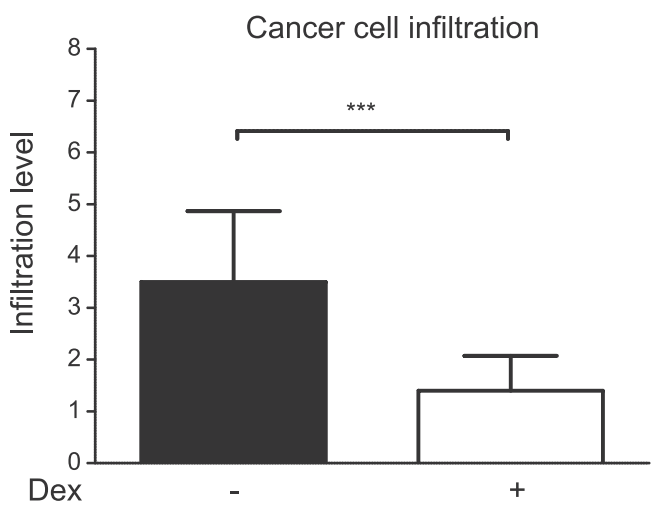

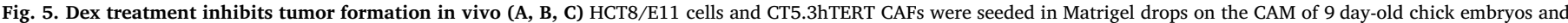

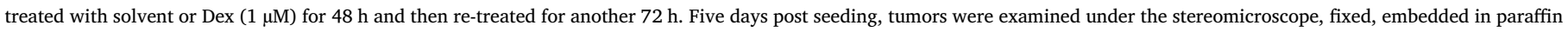

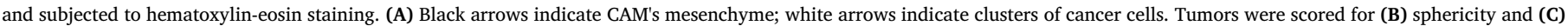

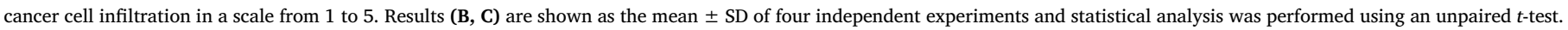
$* * *$ : $p<0.001$. 
These combined factors contribute, directly or indirectly but collectively, to observed effects on cancer cell growth and invasiveness. Therefore, further studies on the endogenous and treatment-affected CAF secretomes are needed to decipher this complex mechanism.

\section{Acknowledgements}

Z. Drebert was supported by the Special Research Fund of the UGent (BOF-UGent) (grant number 01D02011T) and since October 2014 she is supported by the Research Foundation-Flanders (FWO-Vlaanderen) (grant number 1.1.Z75.15.N.00). I.M. Beck was supported by the Research Foundation-Flanders (FWO-Vlaanderen; grant number 1.2.405.10.N.00). None of the aforementioned funding bodies had any active part in preparing the manuscript.

We convey our gratitude to Marleen De Meulemeester, Glenn Wagemans, and Dr. Lynn Feys. The authors have no conflicts of interest to disclose.

\section{Appendix A. Supporting information}

Supplementary data associated with this article can be found in the online version at http://dx.doi.org/10.1016/j.yexcr.2017.11.034.

\section{References}

[1] L.A. Torre, F. Bray, R.L. Siegel, J. Ferlay, J. Lortet-Tieulent, A. Jemal, Global cancer statistics, 2012, CA Cancer J. Clin. 65 (2) (2015) 87-108.

[2] A.T. Chan, E.L. Giovannucci, Primary prevention of colorectal cancer, Gastroenterology 138 (6) (2010) 2029-2043 (e10).

[3] D. Hanahan, R.A. Weinberg, Hallmarks of cancer: the next generation, Cell 144 (5) (2011) 646-674.

[4] F.R. Balkwill, M. Capasso, T. Hagemann, The tumor microenvironment at a glance, J. Cell Sci. 125 (Pt 23) (2012) 5591-5596.

[5] R. Kalluri, The biology and function of fibroblasts in cancer, Nat. Rev. Cancer 16 (9) (2016) 582-598.

[6] L. Mueller, F.A. Goumas, M. Affeldt, S. Sandtner, U.M. Gehling, S. Brilloff, J. Walter, N. Karnatz, K. Lamszus, X. Rogiers, D.C. Broering, Stromal fibroblasts in colorectal liver metastases originate from resident fibroblasts and generate an inflammatory microenvironment, Am. J. Pathol. 171 (5) (2007) 1608-1618.

[7] O. De Wever, P. Demetter, M. Mareel, M. Bracke, Stromal myofibroblasts are drivers of invasive cancer growth, Int. J. Cancer 123 (10) (2008) 2229-2238.

[8] O. De Wever, M. Mareel, Role of myofibroblasts at the invasion front, Biol. Chem. 383 (1) (2002) 55-67.

[9] E. De Vlieghere, L. Verset, P. Demetter, M. Bracke, O. De Wever, Cancer-associated fibroblasts as target and tool in cancer therapeutics and diagnostics, Virchows Arch. 467 (4) (2015) 367-382.

[10] J. Tommelein, L. Verset, T. Boterberg, P. Demetter, M. Bracke, O. De Wever, Cancerassociated fibroblasts connect metastasis-promoting communication in colorectal cancer, Front. Oncol. 5 (2015) 63.

[11] The website of the National Cancer Institute 〈https://www.cancer.gov〉, Consulted December, 2016.

[12] M.B. Meads, R.A. Gatenby, W.S. Dalton, Environment-mediated drug resistance: a major contributor to minimal residual disease, Nat. Rev. Cancer 9 (9) (2009) 665-674.

[13] B.D. Keith, Systematic review of the clinical effect of glucocorticoids on nonhematologic malignancy, BMC Cancer 8 (2008) 84.

[14] T. Rhen, J.A. Cidlowski, Antiinflammatory action of glucocorticoids-new mechanisms for old drugs, N. Engl. J. Med. 353 (16) (2005) 1711-1723.

[15] S. Vandevyver, L. Dejager, C. Libert, On the trail of the glucocorticoid receptor: into the nucleus and back, Traffic 13 (3) (2012) 364-374.

[16] I.M. Beck, W. Vanden Berghe, L. Vermeulen, K.R. Yamamoto, G. Haegeman, K. De Bosscher, Crosstalk in inflammation: the interplay of glucocorticoid receptor-based mechanisms and kinases and phosphatases, Endocr. Rev. 30 (7) (2009) 830-882.

[17] P.J. Barnes, Corticosteroids: the drugs to beat, Eur. J. Pharmacol. 533 (1-3) (2006) $2-14$

[18] D.H. Darrow, A.K. Greene, A.J. Mancini, A.J. Nopper, Diagnosis and management of infantile hemangioma, Pediatrics 136 (4) (2015) e1060-e1104.

[19] S. Greenstein, K. Ghias, N.L. Krett, S.T. Rosen, Mechanisms of glucocorticoidmediated apoptosis in hematological malignancies, Clin. Cancer Res. 8 (6) (2002) $1681-1694$.

[20] P.A. Volden, S.D. Conzen, The influence of glucocorticoid signaling on tumor progression, Brain Behav. Immun. 30 (Suppl) (2013) S26-S31.

[21] R.A. Smith, R.A. Lea, S.R. Weinstein, L.R. Griffiths, Progesterone, glucocorticoid, but not estrogen receptor mRNA is altered in breast cancer stroma, Cancer Lett. 255 (1) (2007) $77-84$.

[22] S. Theocharis, G. Kouraklis, A. Margeli, E. Agapitos, S. Ninos, G. Karatzas, A. Koutselinis, Glucocorticoid receptor (GR) immunohistochemical expression is correlated with cell cycle-related molecules in human colon cancer, Dig. Dis. Sci. 48
(9) (2003) 1745-1750.

[23] Z. Chen, X. Lan, D. Wu, B. Sunkel, Z. Ye, J. Huang, Z. Liu, S.K. Clinton, V.X. Jin, Q. Wang, Ligand-dependent genomic function of glucocorticoid receptor in triplenegative breast cancer, Nat. Commun. 6 (2015) 8323.

[24] Z. Drebert, M. Bracke, I.M. Beck, Glucocorticoids and the non-steroidal selective glucocorticoid receptor modulator, compound A, differentially affect colon cancerderived myofibroblasts, J. Steroid Biochem. Mol. Biol. 149 (2015) 92-105.

[25] Z. Drebert, M. MacAskill, D. Doughty-Shenton, K. De Bosscher, M. Bracke, P.W. Hadoke, I.M. Beck, Colon cancer-derived myofibroblasts increase endothelial cell migration by glucocorticoid-sensitive secretion of a pro-migratory factor, Vasc. Pharmacol. 89 (2017) 19-30.

[26] T. Nakamura, S. Mizuno, The discovery of hepatocyte growth factor (HGF) and its significance for cell biology, life sciences and clinical medicine, Proc. Jpn Acad. Ser. B Phys. Biol. Sci. 86 (6) (2010) 588-610.

[27] C.S. Swindle, K.T. Tran, T.D. Johnson, P. Banerjee, A.M. Mayes, L. Griffith, A. Wells, Epidermal growth factor (EGF)-like repeats of human tenascin-C as ligands for EGF receptor, J. Cell Biol. 154 (2) (2001) 459-468.

[28] O. De Wever, Q.D. Nguyen, L. Van Hoorde, M. Bracke, E. Bruyneel, C. Gespach, M. Mareel, Tenascin-C and SF/HGF produced by myofibroblasts in vitro provide convergent pro-invasive signals to human colon cancer cells through RhoA and Rac, FASEB J. 18 (9) (2004) 1016-1018.

[29] S.J. Vermeulen, E.A. Bruyneel, M.E. Bracke, G.K. De Bruyne, K.M. Vennekens, K.L. Vleminckx, G.J. Berx, F.M. van Roy, M.M. Mareel, Transition from the noninvasive to the invasive phenotype and loss of alpha-catenin in human colon cancer cells, Cancer Res. 55 (20) (1995) 4722-4728.

[30] L. Feys, B. Descamps, C. Vanhove, S. Vermeulen, J.O. Vandesompele, K. Vanderheyden, K. Messens, M. Bracke, O. De Wever, Quantitative and functional requirements for bioluminescent cancer models, In Vivo 30 (1) (2016) 1-11.

[31] M.G. Brattain, W.D. Fine, F.M. Khaled, J. Thompson, D.E. Brattain, Heterogeneity of malignant cells from a human colonic carcinoma, Cancer Res. 41 (5) (1981) $1751-1756$.

[32] E. De Vlieghere, F. Gremonprez, L. Verset, L. Marien, C.J. Jones, B. De Craene, G. Berx, B. Descamps, C. Vanhove, J.P. Remon, W. Ceelen, P. Demetter, M. Bracke, B.G. De Geest, O. De Wever, Tumor-environment biomimetics delay peritoneal metastasis formation by deceiving and redirecting disseminated cancer cells, Biomaterials 54 (2015) 148-157.

[33] K. De Bosscher, W. Vanden Berghe, I.M. Beck, W. Van Molle, N. Hennuyer, J. Hapgood, C. Libert, B. Staels, A. Louw, G. Haegeman, A fully dissociated compound of plant origin for inflammatory gene repression, Proc. Natl. Acad. Sci. USA 102 (44) (2005) 15827-15832.

[34] W. Vanden Berghe, S. Plaisance, E. Boone, K. De Bosscher, M.L. Schmitz, W. Fiers, G. Haegeman, p38 and extracellular signal-regulated kinase mitogen-activated protein kinase pathways are required for nuclear factor-kappaB p65 transactivation mediated by tumor necrosis factor, J. Biol. Chem. 273 (6) (1998) 3285-3290.

[35] O.H. Lowry, N.J. Rosebrough, A.L. Farr, R.J. Randall, Protein measurement with the Folin phenol reagent, J. Biol. Chem. 193 (1) (1951) 265-275.

[36] C.A. Schneider, W.S. Rasband, K.W. Eliceiri, NIH Image to ImageJ: 25 years of image analysis, Nat. Methods 9 (7) (2012) 671-675.

[37] M. Toth, R. Fridman, Assessment of Gelatinases (MMP-2 and MMP-9) by Gelatin Zymography, Methods Mol. Med 57 (2001) 163-174.

[38] V. Vichai, K. Kirtikara, Sulforhodamine B colorimetric assay for cytotoxicity screening, Nat. Protoc. 1 (3) (2006) 1112-1116.

[39] O. De Wever, A. Hendrix, A. De Boeck, W. Westbroek, G. Braems, S. Emami, M. Sabbah, C. Gespach, M. Bracke, Modeling and quantification of cancer cell invasion through collagen type I matrices, Int. J. Dev. Biol. 54 (5) (2010) 887-896.

[40] M. Van Bockstal, K. Lambein, M. Van Gele, E. De Vlieghere, R. Limame, G. Braems, R. Van den Broecke, V. Cocquyt, H. Denys, M. Bracke, L. Libbrecht, O. De Wever, Differential regulation of extracellular matrix protein expression in carcinoma-associated fibroblasts by TGF-beta1 regulates cancer cell spreading but not adhesion, Oncoscience 1 (10) (2014) 634-648.

[41] G.M. Sys, L. Lapeire, N. Stevens, H. Favoreel, R. Forsyth, M. Bracke, O. De Wever, The in ovo CAM-assay as a xenograft model for sarcoma, J. Vis. Exp. 77 (2013) e50522.

[42] J. Hoppstadter, A.K. Kiemer, Glucocorticoid-induced leucine zipper (GILZ) in immuno suppression: master regulator or bystander? Oncotarget 6 (36) (2015) $38446-38457$.

[43] R. Roy, J. Yang, M.A. Moses, Matrix metalloproteinases as novel biomarkers and potential therapeutic targets in human cancer, J. Clin. Oncol. 27 (31) (2009) $5287-5297$.

[44] Z. Drebert, M. MacAskill, D. Doughty-Shenton, K. De Bosscher, M. Bracke, P.W. Hadoke, I.M. Beck, Colon cancer-derived myofibroblasts increase endothelial cell migration by glucocorticoid-sensitive secretion of a pro-migratory factor, Vasc. Pharmacol. (2016).

[45] A.C. Tufan, N.L. Satiroglu-Tufan, The chick embryo chorioallantoic membrane as a model system for the study of tumor angiogenesis, invasion and development of anti-angiogenic agents, Curr. Cancer Drug Targets 5 (4) (2005) 249-266.

[46] H.E. Barker, J.T. Paget, A.A. Khan, K.J. Harrington, The tumour microenvironment after radiotherapy: mechanisms of resistance and recurrence, Nat. Rev. Cancer 15 (7) (2015) 409-425.

[47] P. Cirri, P. Chiarugi, Cancer associated fibroblasts: the dark side of the coin, Am. J. Cancer Res. 1 (4) (2011) 482-497.

[48] Z. Yang, T.R. Kyriakides, P. Bornstein, Matricellular proteins as modulators of cellmatrix interactions: adhesive defect in thrombospondin 2-null fibroblasts is a consequence of increased levels of matrix metalloproteinase-2, Mol. Biol. Cell 11 (10) (2000) 3353-3364.

[49] M.L. Patterson, S.J. Atkinson, V. Knauper, G. Murphy, Specific collagenolysis by 
gelatinase A, MMP-2, is determined by the hemopexin domain and not the fibronectin-like domain, FEBS Lett. 503 (2-3) (2001) 158-162.

[50] P. Friedl, S. Alexander, Cancer invasion and the microenvironment: plasticity and reciprocity, Cell 147 (5) (2011) 992-1009.

[51] C.D. Paul, P. Mistriotis, K. Konstantopoulos, Cancer cell motility: lessons from migration in confined spaces, Nat. Rev. Cancer 17 (2) (2016) 131-140.

[52] S. Han, N.T. Bui, M.T. Ho, Y.M. Kim, M. Cho, D.B. Shin, Dexamethasone inhibits TGF-beta1-induced cell migration by regulating the ERK and AKT pathways in human colon cancer cells via CYR61, Cancer Res. Treat. 48 (3) (2016) 1141-1153.

[53] J.H. Kim, Y.J. Hwang, S.H. Han, Y.E. Lee, S. Kim, Y.J. Kim, J.H. Cho, K.A. Kwon, S.H. Kim, Dexamethasone inhibits hypoxia-induced epithelial-mesenchymal transition in colon cancer, World J. Gastroenterol. 21 (34) (2015) 9887-9899.

[54] C. Zhang, T. Wenger, J. Mattern, S. Ilea, C. Frey, P. Gutwein, P. Altevogt,
W. Bodenmuller, N. Gassler, P.A. Schnabel, H. Dienemann, A. Marme,

M. Hohenfellner, A. Haferkamp, J. Pfitzenmaier, H.J. Grone, A. Kolb, P. Buchler, M. Buchler, H. Friess, W. Rittgen, L. Edler, K.M. Debatin, P.H. Krammer, H.P. Rutz, I. Herr, Clinical and mechanistic aspects of glucocorticoid-induced chemotherapy resistance in the majority of solid tumors, Cancer Biol. Ther. 6 (2) (2007) 278-287.

[55] Y.M. Lin, H.J. Jan, C.C. Lee, H.Y. Tao, Y.L. Shih, H.W. Wei, H.M. Lee, Dexamethasone reduced invasiveness of human malignant glioblastoma cells through a MAPK phosphatase-1 (MKP-1) dependent mechanism, Eur. J. Pharmacol. $593(1-3)(2008) 1-9$.

[56] Y. Zheng, K. Izumi, Y. Li, H. Ishiguro, H. Miyamoto, Contrary regulation of bladder cancer cell proliferation and invasion by dexamethasone-mediated glucocorticoid receptor signals, Mol. Cancer Ther. 11 (12) (2012) 2621-2632. 